\title{
A Digital First Primary Care Model in the National Health Service (NHS): A Perspective from a Digital Health Provider
}

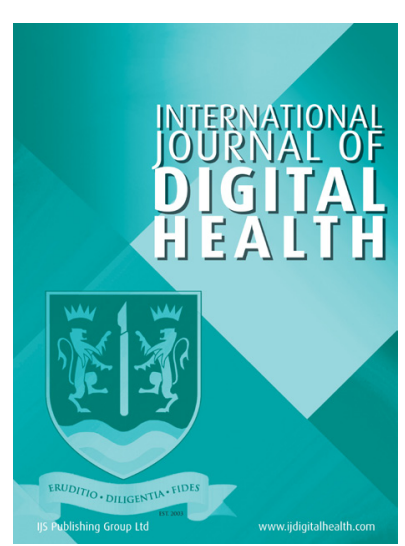

\author{
MAZIN AL-SAFFAR (D) \\ MATTHEW NOBLE (D)
}

TEJAL PATEL (D)

SHIRJEEL TAHIR

FRANK SCHNEIDER

${ }^{*}$ Author affiliations can be found in the back matter of this article

\section{ABSTRACT}

Primary care has been instrumental in delivering high quality care since the inception of the National Health Service (NHS) in the UK. However, increased complexity and demand in the system has resulted in difficulty in accessing clinicians and low morale in the workforce. Policy makers have recognised that new models of care need to be implemented to fulfil patients' needs. Technology is expanding at a rapid pace with a potential to improve patient care. The devastating impact of COVID-19 has highlighted the need to implement innovative digital solutions in the system. However, lack of resources, physician reluctance and digital literacy issues have highlighted the gaps in the NHS. A Digital First model of care has the potential to provide high quality care to all patients in the community setting. The clinical workforce is key to this transformation, policy makers should provide them with the best resources to implement this vision.

The authors discuss the challenges that General Practice has faced and their experience of delivering a Digital First model of Primary Care in the NHS, highlighting that there is an emphasis on self-care and easy accessibility for patients in the post-COVID world. Further work must take place to tackle digital literacy and research into the benefits of a Digital First model of care. 


\section{INTRODUCTION}

General Practice has been vital to the National Health Service (NHS) since its inception in 1948. However, significant pressures in the healthcare system have resulted in burnout amongst General Practitioners (GPs) and difficulties in recruitment [1]. In response to this, NHS England acknowledged that patients are now living longer with more complex health conditions, that there is no 'one size fits all' model of care [2]. Furthermore, the authors recognised that technology will play a vital part in delivering high quality care and encouraged a roll out of new models that are relevant to a community's health needs [2, 3]. The NHS long term plan made a commitment that all patients should have access to digital first primary care by 2023 [4]. We discuss the benefits of a Digital First model of care and our experiences as one of the first organisations to implement this in the NHS.

\subsection{PRIMARY CARE IN THE UK}

The NHS has been ranked as one of the top amongst other industrialised countries around the world, for its safety, affordability and accessibility [5]. General Practice has been a vital part of this success and has been described as 'the jewel in the crown' of the NHS [6]. Primary care staff are in a privileged position to act as the gateway to the NHS and enhance the lives of patients. However, others have argued that with a reduction of funding to General Practice, we will not be able to sustain this 'fading jewel in the crown' [7]. Primary care workload has increased in complexity, with a $13 \%$ increase in physical appointments and a $65 \%$ increase in telephone consultations between 2010/2011 to 2014/2015 [1]. In response to this, NHS England has committed an additional $£ 2.4$ billion a year by $2020 / 2021$ to invest in premises, staff and technology through its ' $\mathrm{GP}$ forward View' programme [8]. As part of this programme, there has been an additional investment in promoting 'online consultation' systems for all GP practices [8]. The workforce is vital for the success of these new proposals, however with the increase in workload and low morale, we must find ways to develop their skills for the General Practice of tomorrow [9]. Health Education England (HEE) recognised that we must prepare the NHS workforce for the digital future, by developing their skills in online consultations and the use of Artificial Intelligence (A.I) to supplement their clinical skills [10].

\section{TRADITIONAL GENERAL PRACTICE}

Over the years, General Practice consultations have not significantly changed. Face-to-face consultations have an important role in the diagnosis and management of complex health issues. However, the NHS has explored implementing alternatives to the physical consult.
Telephone triage has traditionally been used to meet the demands in primary care, the aim of which is to reduce physical appointments [11, 12]. Technology has been rapidly evolving in major sectors such as banking and transport [13]. Yet the NHS has been slow in adopting such methods, particularly as patients' have more technology available to them to monitor and manage their health, moving to more personalised health care and doctors acting as advisors [13].

\subsection{THE CASE FOR A 'DIGITAL FIRST' PRIMARY CARE}

Moore's Law has predicted that computer chips would double in speed every 18 months [14]. This increase in the speed of computer chips have largely proven to be an accurate prediction, leading to significant technological advances over the years. These technological advances have allowed society the capability of using smartphones to manage their lives. Healthcare systems across the world have been slow to implement technology in routine care. Early trials of telemedicine in secondary care have shown that there is evidence of a reduction in hospital admissions and mortality rates [15]. Until recently, the extension of such technology into primary care has yet to be accomplished. Low uptake of digital technology in primary care has been associated with reluctance from clinicians to move away from a traditional model, lack of appropriate equipment and security issues [16]. Evidence suggests that the uptake of digital consultations is mainly amongst the young, healthy and affluent population [16]. However, there has been no definitive data to confirm this. Moreover, there is a 'Digital Literacy' gap amongst patients. Digital literacy is defined as "those capabilities that fit someone for living, learning, working, participating and thriving in a digital society" [17]. There is evidence suggesting that those over 65 years old have the lowest share of internet access, though this gap is narrowing over time [18]. Patients are more likely to use this technology if they are supported by clinicians in using their medical records to promote self-care and is easily accessible [19]. A Digital First model of care provides online access to primary care in the first instance. A Digital First model empowers patients to selfcare when they can (through a range of tools such as a symptom checker) and access to digital consultations (video) when they require it. Digital consultations enable the needs of patients to be assessed and provide appropriate treatment. When this is not possible patients are invited to a physical appointment with their Primary Care clinician.

\subsection{DIGITAL FIRST AND COVID-19}

The COVID-19 pandemic had resulted in a devastating impact on society. Healthcare across the globe has been under tremendous pressure with inpatient admissions on the rise. This has unfortunately had a knock-on effect on 
routine care. The British Medical Association (BMA) has estimated that between April and December 2020, there were 2.7 million fewer elective procedures and 18.7 million fewer outpatient attendances [20]. It is also estimated that there were 280,000 fewer urgent cancer referrals between April and June 2020 [21]. Healthcare organisations and policy makers have had to radically alter the way care was delivered during this crisis. Preliminary studies from a sample size of 809 GP practices, has shown that $76 \%$ of GP practices have now established video consulting as a direct response to Covid-19 compared to only $20 \%$ before the pandemic [22]. NHS England has also indicated that video consultations are now available in $99 \%$ of GP practices to promote a Digital First model of care [23].

A Digital First approach has been shown to ease the pressure on the system [24]. Healthcare professionals have the ability to screen patients in real time and provide appropriate advice without putting vulnerable patients and staff at risk [24]. National bodies have provided GP practices with guidance on remote consultations using platforms such as Skype and WhatsApp [25].

Although the shift to a digital first model has been encouraging, it does require patients to have access to the internet. Adequate support should be provided to those who either require access to the internet or need help in understanding how to operate the digital platform. However, many are unable to access healthcare through a Digital First model resulting in unequal access and a two-tier system. Whilst access to digital healthcare will always be more convenient and can be arranged at short notice (as it does not require travel), we still have a duty to ensure that those without digital healthcare are not increasingly disadvantaged by making it harder to access physical appointments [26].

\section{DIGITAL FIRST PRIMARY CARE IN PRACTICE}

Babylon Health is a digital health company that has developed a mobile health app allowing patients to access an Artificial Intelligence (A.I) driven symptoms checker and video consultations with clinicians. The organisation has partnerships across the world such as the NHS (UK) and the government of Rwanda [27]. Patients can choose the type of clinician, make an appointment and access their consultation notes. GP at Hand (GPaH) (the NHS practice powered by Babylon Health) has implemented a Digital First model in London and Birmingham. GPaH offers patients digital access to patients and physical appointments across eight sites in the two cities [28]. Approximately 15-20\% of patients will subsequently need physical appointments following a digital consultation [29]. In collaboration with Hammersmith and Fulham Clinical Commissioning Group(CCG), GPaH has over 90,000 patients registered on its list [30].
The Organisation has used its existing infrastructure during the COVID-19 pandemic. Recognising that patients needed accurate and up-to-date information, the 'COVID-19 Care Assistant' was launched for NHS patients. The assistant provides information on self-management as well as providing the option to speak directly with a clinician using a live chat function [31]. As a service already digitally enabled at the first point of contact, patients are then signposted to speak to a clinician via video consultation if needed. This means that existing $\mathrm{GPaH}$ Primary Care services are not flooded with COVID-19 queries. The development of the COVID-19 Care Assistant, highlights the need to establish an infrastructure that responds to new challenges and demands without adversely affecting existing services.

\subsection{WORKFORCE CONSIDERATIONS}

The digital workforce is vital to the future of an evolving healthcare system. GPaH patients have access to a team of: GPs, advanced nurse practitioners, physiotherapists, pharmacists and mental health nurses. This clinical skill mix represents the current landscape of primary care clinicians seen in traditional practices [32]. Recognising that some patients have complex needs, GPaH has a multi-professional Care Coordination Team (CCT) [33]. The CCT is a multi-professional clinical team whose main aim is to coordinate the care of patients with complex care needs ensuring that they have continuity of care. Clinicians undergo a digital training programme to ensure they are practicing safely and confidently in the remote setting. A quality assurance team has been developed to guarantee that clinicians deliver the highest quality of care and ensure that they are well supported throughout their digital health journey. An independent evaluation of $\mathrm{GPaH}$ indicated that staff felt satisfied working as remote clinicians and well supported despite working in isolation [34].

\section{DISCUSSION}

Digital Health has the potential to transform the way we deliver care to patients for the better. Technology is evolving at a very rapid pace and healthcare has a role to utilise this to meet patients' needs. Policy makers in the UK have encouraged the development of alternative models of care through the 'Five year forward view' and the 'NHS Long Term Plan'. The use of innovative digital solutions will be vital in this journey [2, 4]. In response to this, NHSX was created by the UK government in an effort to drive digital transformation in the health system [35]. These proposals have been encouraging and as a result this has led to the development of numerous online GP apps within the NHS and private sector. The NHS is known for its health care system due to its multi-professional workforce [5]. The workforce must now adapt to the rapid 
evolution of technology and policy makers need to act to build an infrastructure in collaboration with experts in the field $[10,19]$.

Babylon Health has implemented a Digital First model of care in the complex organisational structure of the NHS [36]. Although there were concerns that GPaH might not meet the needs of those with complex health issues, we argue that the development of a multi-professional workforce such as the CCT has proven that this can work for all patients. The digital workforce is satisfied with this model of care and there is high morale in a wellsupported environment [34]. Evidence has shown that health care staff who feel valued and supported bring positive outcomes throughout all levels of the system [37]. The COVID-19 pandemic has demonstrated that there is a willingness from both patients and the wider primary care community in adopting this technology.

There is a duty to extend this model of care to those who are vulnerable and disadvantaged. The NHS widening digital participation programme (from 20132016) demonstrated it was possible to reach digitally excluded groups such as those in deprived communities [38]. Through the development of local digital health information networks and face-to-face support, 59\% of patients felt they were able to access and use online information resulting in $21 \%$ fewer GP appointments [38]. It is vital that partnerships are formed with local providers, commissioners and patients to co-produce digital services that meet the populations' needs to prevent further digital inequalities [39].

\section{CONCLUSION}

The health needs of our patients have significantly changed over the years. Patients are now living longer with more complex health conditions. There is therefore a duty to provide the highest quality of care with an emphasis on access to a healthcare professional. The rapid advancement of technology has resulted in a major transformation in several industries. Until recently healthcare has lagged in implementing digital solutions. The COVID-19 pandemic has transformed the way healthcare is delivered. Babylon Health's Digital First model is an example of how this can be implemented in the NHS. Other Digital First models are also being developed in England, demonstrating the benefits for patients and staff $[40,41]$. Further research into and evaluation of models that integrate digital consultations within the NHS Primary Care system is needed. Although the NHS has developed programmes to tackle digital literacy issues in the community, the COVID-19 pandemic has exposed these issues at a much larger scale. NHS organisations, the voluntary sector and policy makers, should collaborate to enhance access to Digital First models of care for vulnerable patients.

\section{COMPETING INTERESTS}

Mazin Alsaffar is a member of the editorial board for the International Journal of Digital Health, this is on a voluntary basis. All other authors have no competing interests.

\section{AUTHOR CONTRIBUTIONS}

Mazin Alsaffar: Conceptualization, formal analysis, Writing - Original draft. Matthew Noble: Supervision, Writing - Review \& Editing. Shirjeel Tahir: Supervision, Writing - Review \& Editing. Frank Schneider: Supervision, Writing - Review \& Editing. Tejal Patel: Supervision, Writing - Review \& Editing.

\section{AUTHOR AFFILIATIONS}

Mazin Al-saffar (iD orcid.org/0000-0003-0454-8754 Babylon Health, 60 Sloane Avenue, SW3 3DD, London, GB

Matthew Noble (D) orcid.org/0000-0003-1174-186X Babylon Health, 60 Sloane Avenue, SW3 3DD, London, GB

Tejal Patel (D) orcid.org/0000-0002-7356-7054 Babylon Health, 60 Sloane Avenue, SW3 3DD, London, GB Shirjeel Tahir

Babylon Health, 60 Sloane Avenue, SW3 3DD, London, GB Frank Schneider

Babylon Health, 60 Sloane Avenue, SW3 3DD, London, GB

\section{REFERENCES}

1. Kings Fund. Understanding pressures in general practice. Kings Fund. 2016. https://www.kingsfund.org.uk/ publications/pressures-in-general-practice (accessed December 13, 2020).

2. NHS England. NHS Five Year Forward View. 2014. https:// www.england.nhs.uk/five-year-forward-view/ (accessed December 10, 2020).

3. NHS England. New Care Models. n.d. https://www. england.nhs.uk/new-care-models/ (accessed December 30, 2020).

4. NHS England. NHS Long Term Plan. n.d. https://www. longtermplan.nhs.uk (accessed August 28, 2020).

5. Schneider E, Sarnak D, Squires D, Shah A, Doty M. Mirror, Mirror 2017: International Comparison. 2017. https://www. commonwealthfund.org/publications/fund-reports/2017/ jul/mirror-mirror-2017-international-comparison-reflectsflaws-and (accessed December 14, 2020).

6. Marshall M. A Precious Jewel - The Role of General Practice in the English NHS. N. Engl. J. Med. 2015; 372 : 893-897. DOI: https://doi.org/10.1056/NEJMp1411429

7. Majeed A. Primary care: a fading jewel in the NHS crown. Lond. J. Prim. Care. 2015; 7: 89-91. DOI: https://doi.org/10.1 080/17571472.2015.1082343 
8. NHS England. General Practice Forward View (GPFV). 2016. https://www.england.nhs.uk/publication/general-practiceforward-view-gpfv/ (accessed December 14, 2020).

9. Pulse. More than $75 \%$ of GPs say morale is worse than when they started practising. 2020. https://www. pulsetoday.co.uk/news/uncategorised/more-than-75-ofgps-say-morale-is-worse-than-when-they-startedpractising/ (accessed December 14, 2020).

10. Health Education England. Topol review. 2018. https:// www.hee.nhs.uk/our-work/topol-review (accessed December 14, 2020).

11. Khan MNB. Telephone consultations in primary care, how to improve their safety, effectiveness and quality. BMJ Open Qual. 2013; 2: u202013.w1227. DOI: https://doi. org/10.1136/bmjquality.u202013.w1227

12. Holt TA, Fletcher E, Warren F, Richards S, Salisbury C, Calitri R, Green C, Taylor R, Richards DA, Varley A, Campbell J. Telephone triage systems in UK general practice: analysis of consultation duration during the index day in a pragmatic randomised controlled trial. Br. J. Gen. Pract. 2016; 66: e214-e218. DOI: https://doi.org/10.3399/ bjgp16X684001

13. Young AJ. New technologies and general practice. Br. J. Gen. Pract. 2016; 66: 601-602. DOI: https://doi.org/10.3399/ bjgp16X688021

14. Bell L. What is Moore's Law? Wired UK. 2016. https://www. wired.co.uk/article/wired-explains-moores-law (accessed December 15, 2020).

15. Stevenson A, Bardsley M. The impact of telehealth on use of hospital care and mortality. Nuffield Trust. 2012. https://www. nuffieldtrust.org.uk/research/the-impact-oftelehealth-on-use-of-hospital-care-and-mortality (accessed December 30, 2020).

16. Rodgers M, Raine G, Thomas S, Harden M, Eastwood A. Informing NHS policy in 'digital-first primary care': a rapid evidence synthesis. Health Serv. Deliv. Res. 2019; 7 1-124. DOI: https://doi.org/10.3310/hsdr07410

17. Health Education England, Digital literacy of the wider workforce, (2018). https://www.hee.nhs.uk/our-work/ digital-literacy (accessed March 4, 2021).

18. Beaney P, Odulaja A, Hadley A, Prince C, OBE RC. GP Online: turning expectations into reality with the new NHS app. Br. J. Gen. Pract. 2019; 69: 172-173. DOI: https://doi. org/10.3399/bjgp19X701333

19. The Nuffield Trust. The digital patient: transforming primary care?. 2017. https://www.nuffieldtrust.org.uk/ research/the-digital-patient-transforming-primary-care (accessed December 10, 2020).

20. Dyson M. Pressure points in the NHS. Br. Med. Assoc. Trade Union Prof. Body Dr. UK. n.d. https://www.bma.org.uk/ advice-and-support/nhs-delivery-and-workforce/pressures/ pressure-points-in-the-nhs (accessed December 17, 2020).

21. Nagpaul C. The hidden impact of COVID-19. The BMA. 2020. https://www.bma.org.uk/news-and-opinion/thehidden-impact-of-covid-19 (accessed December 30, 2020).
22. Shaw S, Hughes G. Video consulting in the UK NHS - how far have we come and how far should we go? - Nuffield Department of Primary Care Health Sciences. University of Oxford. 2020. https://www.phc.ox.ac.uk/news/blog/ video-consulting-in-the-uk-nhs-2013-how-far-have-wecome-and-how-far-should-we-go (accessed March 7, 2021).

23. Bakhai M. The use of online and video consultations during the COVID-19 pandemic - delivering the best care to patients. NHSX. 2020. https://www.nhsX.nhs.uk/blogs/ use-online-and-video-consultations-during-covid-19pandemic-delivering-best-care-patients/ (accessed March 10, 2021).

24. Fagherazzi G, Goetzinger C, Rashid MA, Aguayo GA, Huiart L. Digital Health Strategies to Fight COVID-19 Worldwide: Challenges, Recommendations, and a Call for Papers. J. Med. Internet Res. 2020; 22: 10. DOI: https://doi. org/10.2196/19284

25. Hutchings R. The impact of Covid-19 on the use of digital technology in the NHS. Nuffield Trust. 2020. https://www. nuffieldtrust.org.uk/research/the-impact-of-covid-19on-the-use-of-digital-technology-in-the-nhs (accessed December 17, 2020).

26. Majeed A, Msile E, Coronini-cronberg S. Covid-19 is magnifying the digital divide. BMJ Opin. 2020. https://blogs. bmj.com/bmj/2020/09/01/covid-19-is-magnifying-thedigital-divide/ (accessed December 17, 2020).

27. Babylon Health. Babylon Health. n.d. https://www. babylonhealth.com/about (accessed December 16, 2020).

28. Babylon Health. GP at hand. n.d. https://www.gpathand. nhs.uk/ (accessed December 16, 2020).

29. Burki T. GP at hand: a digital revolution for health care provision? The Lancet. 2019; 394: 457-460. DOI: https://doi. org/10.1016/S0140-6736(19)31802-1

30. Bostock N. GP at Hand on track for largest practice list. GP Online. 2020. https://www.gponline.com/gp-hand-tracklargest-practice-list-england-end-summer/article/1680474 (accessed December 16, 2020).

31. Babylon Health. COVID-19 Care Assistant. Babylon Health. n.d. https://www.babylonhealth.com/coronavirus/covid-19care-assistant (accessed March 7, 2021).

32. Health Education England, Primary care. 2017. https:// www.hee.nhs.uk/our-work/primary-care (accessed December 29, 2020).

33. Babylon Health. What is the Care Coordination team? GP Hand. n.d. https://support.gpathand.nhs.uk/hc/en-us/ articles/360001633497-What-is-the-Care-Coordinationteam- (accessed March 10, 2021).

34. Ipsos Mori. York Health Economics Consortium. Evaluation of Babylon GP at hand. n.d. https://www. hammersmithfulhamccg.nhs.uk/newspublications/ publications-policies.aspx?n=9446 (accessed August 31, 2020).

35. NHSX. n.d. https://www.nhsx.nhs.uk/ (accessed December 16, 2020). 
36. The Kings Fund. How is the NHS structured? Kings Fund. 2020. https://www.kingsfund.org.uk/audio-video/how-isnhs-structured-funding-flow (accessed March 10, 2021).

37. West M, Collins B, Eckert R, Chowla R. Caring to change. Kings Fund. 2017. https://www. kingsfund.org.uk/ publications/caring-change (accessed December 16, 2020).

38. NHS England. Digital Inclusion in Health and Care. n.d. https://www.england.nhs.uk/ltphimenu/digital-inclusion/ digital-inclusion-in-health-and-care/ (accessed December 29, 2020).

39. Stone E, Nuckley P, Shapiro R. Digital Inclusion in Health and Care: Lessons learned from the NHS Widening Digital Participation Programme (2017-2020) | Good Things
Foundation. 2020. https://www.goodthingsfoundation.org/ research-publications/digital-inclusion-health-and-carelessons-learned-nhs-widening-digital (accessed December 30, 2020).

40. NHS England. Primary care - online consultations. n.d. https://www.england.nhs.uk/contact-us/privacy-notice/ how-we-use-your-information/our-services/primary-careonline-consultations/ (accessed March 10, 2021).

41. NHS England. Online appointments increase by $100 \%$ - Hazeldene Medical Centre. London. n.d. https://www. england.nhs.uk/gp/case-studies/online-appointmentsincrease-by-100-hazeldene-medical-centre-london/ (accessed March 10, 2021).

TO CITE THIS ARTICLE:

Al-Saffar M, Noble M, Patel T, Tahir S, Schneider F. A Digital First Primary Care Model in the National Health Service (NHS): A Perspective from a Digital Health Provider. International Journal of Digital Health. 2021; 1(1): 11, 1-6. DOI: https://doi.org/10.29337/ijdh.35

Submitted: 13 January 2021 Accepted: 25 April 2021 Published: 05 May 2021

COPYRIGHT:

(c) 2021 The Author(s). This is an open-access article distributed under the terms of the Creative Commons Attribution-NonCommercial 4.0 International License (CC-BY-NC 4.0), which permits unrestricted distribution, reproduction and adaptation in any medium, provided the original author and source are credited, and that the material is not used for commercial purposes.

See https://creativecommons.org/licenses/by-nc/4.0/.

International Journal of Digital Health is a peer-reviewed open access journal published by IJS Publishing Group. 